\title{
Unravelling the role of Stress regulators on GnRH release in Letrozole induced PCOS rat model
}

Nirja Chaudhari and Laxmipriya P. Nampoothiri*

Department of Biochemistry, The Maharaja Sayajirao University of Baroda, Vadodara- 390002

*Correspondence: Inampoothiri@gmail.com

\section{Introduction}

- Stress is a key physiological response that affects reproductive axis.

- Reproductive axis (HPG) have intrinsic as well as extrinsic regulation through several neuropeptides.

- Novel neuropeptides like RFamide- related peptide3 (RFRP3) (a mammalian orthologue of Gonadotropin-inhibitory hormone (GnIH),

Urocortin2, a neuropeptide belonging to CRF family and others have been identified as stressors (Ubuka et al., 2012; Kageyama, 2013)

- CRH1, RFRP3 and Ucn2 directly interact with GnRH neurons influencing Pituitary gonadotropin release through their receptors-CRHR1, GPR147 and CRFR2 respectively.

- However, such a complex interaction of GnRH axis with stressors and its gonadal function adaptations is poorly understood in PCOS

- Thereby, current study was undertaken to elucidate the interaction of stress regulators with GnRH axis in PCOS pathology using rodent model.

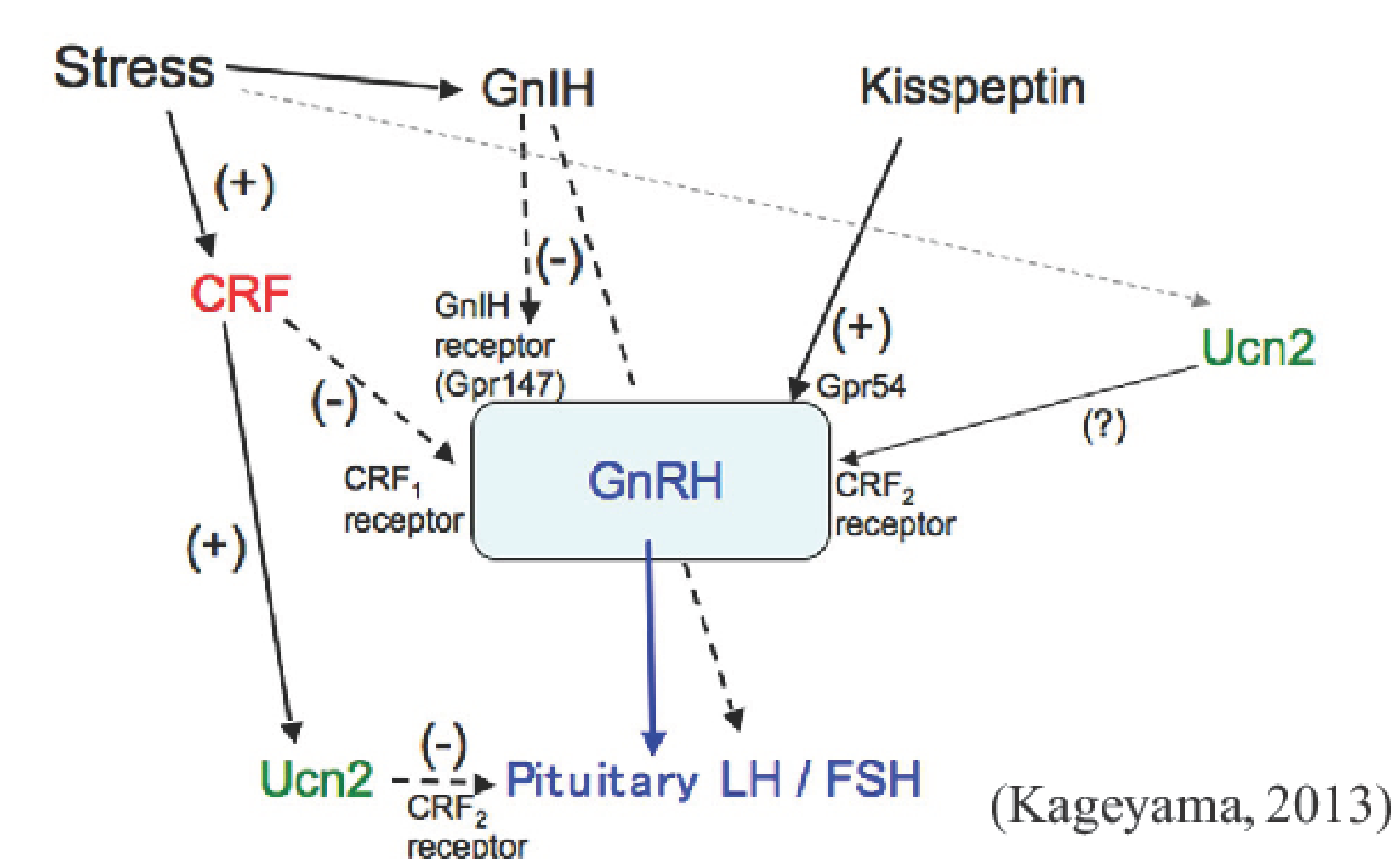

\section{Methods}

1. PCOS induction in rats by using Letrozole-an aromatase inhibitor (Kafali et al., 2004)

2. Estrus cyclicity (Yener et al., 2006)

3. Corticosterone estimation (Pandya and Katyare, 2004)

4. Hormone analysis (Estrogen, Testosterone, progesterone) by ELISA kits

RNA isolated using TRIzol reagent was used for first strand cDNA synthesis and utilized for Real-Time PCR.

\section{Experimental Design}

Induction of PCOS:

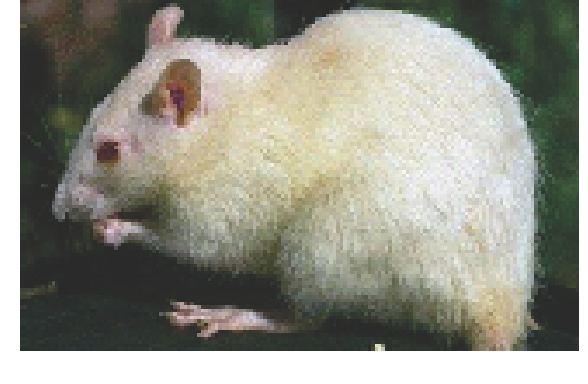

3 months old adult virgin female rats (190-220 gm)
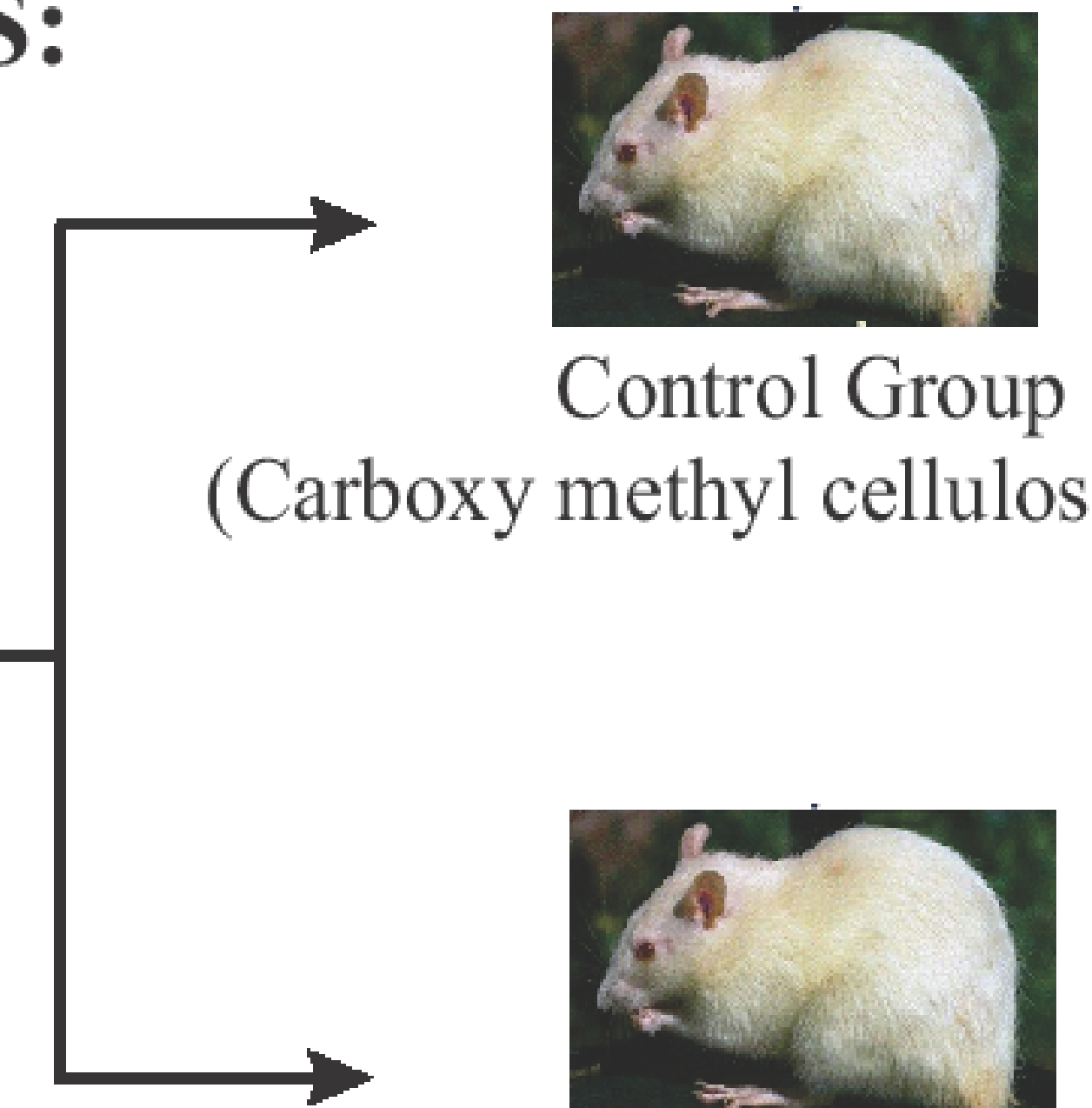

Carboxy methyl cellulose treated)

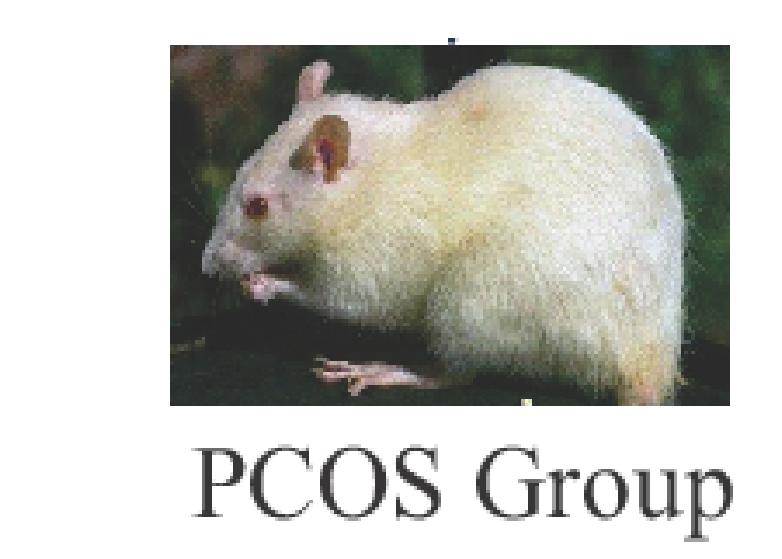

$(0.5 \mathrm{mg} / \mathrm{kg}$ B.W. of Letrozole, orally, daily for 21 days)

Validation of PCOS rat model
Table-1. Serum hormone profile
\begin{tabular}{|l|l|l|}
\hline & \multicolumn{1}{|c|}{ Control } & PCOS \\
\hline Estrogen $(\mathrm{pg} / \mathrm{ml})$ & $132.3 \pm 17.37$ & $139.3 \pm 19.10$ \\
\hline Testosterone $(\mathrm{ng} / \mathrm{ml})$ & $0.3157 \pm 0.055$ & $1.177 \pm 0.072^{* * *}$ \\
\hline Progesterone $(\mathrm{ng} / \mathrm{ml})$ & $12.25 \pm 0.54$ & $9.95 \pm 0.39 *$ \\
\hline Corticosterone $(\mu \mathrm{g} / \mathrm{ml})$ & $5.34 \pm 0.56$ & $11.42 \pm 0.98^{* * *}$ \\
\hline
\end{tabular}

Table-1. Letrozole treated rats showed increased serum testosterone $(\mathrm{P}<0.001)$ and corticosterone $(\mathrm{P}<0.001)$ compared to control group with decreased progesterone content $(\mathrm{P}<0.05)$ and no difference in serum estradiol level.

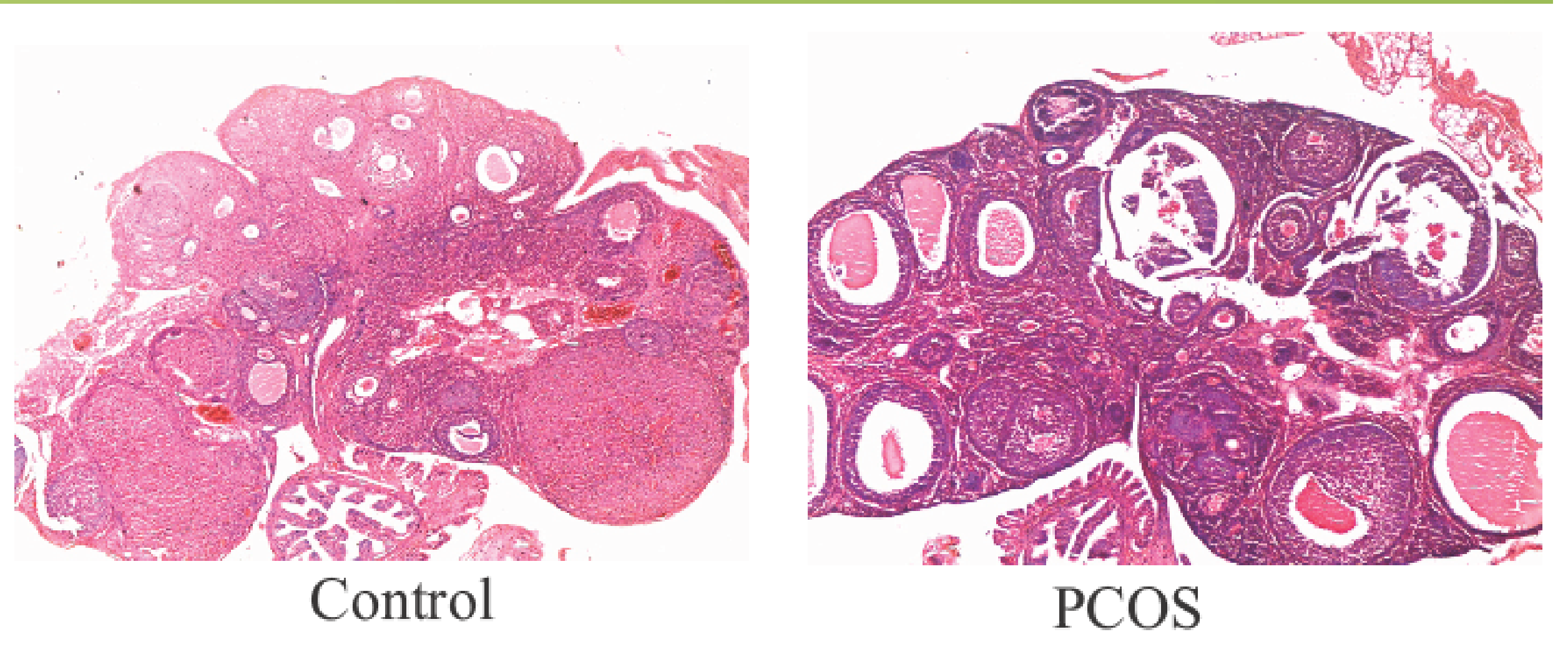

Figure 1.Hematoxylin eosin stained ovarian sections. Control sections show follicles in various stages of development.Treatment group sections demonstrate numerous peripheral fluid-filled cysts $(4 \mathrm{X})$. Letrozole treated animals also demonstrated disturbance in estrus cyclicity and most of the animals showed extended diestrus stage.

Results
\begin{tabular}{|l|c|c|c|c|} 
Table-1. Steroid hormone profile \\
\hline \multicolumn{4}{|c|}{ Pituitary } & \multicolumn{2}{c|}{ Hypothalamus } \\
\hline & Control & PCOS & Control & PCOS \\
\hline $\begin{array}{l}\text { Estrogen } \\
(\mathrm{pg} g \mathrm{~g})\end{array}$ & $340.0 \pm 17.0$ & $237.0 \pm 19.0 * *$ & $227.0 \pm 15.0$ & $139.0 \pm 16.0 * *$ \\
\hline $\begin{array}{l}\text { Progesterone } \\
(\mathrm{pg} / \mathrm{g})\end{array}$ & $1.33 \pm 0.034$ & $0.833 \pm 0.0315^{*}$ & $0.855 \pm 0.03647$ & $0.7981 \pm 0.0431$ \\
\hline $\begin{array}{l}\text { Testosterone } \\
(\mathrm{ng} / \mathrm{g})\end{array}$ & $1.389 \pm 0.056$ & $1.817 \pm 0.0455^{* * *}$ & $1.088 \pm 0.0438$ & $1.40 \pm 0.027 * * *$ \\
\hline $\begin{array}{l}\text { Corticosterone } \\
(\mu \mathrm{g} / \mathrm{g})\end{array}$ & $1.3 \pm 0.051$ & $2.08 \pm 0.087 * 8$ & $1.59 \pm 0.067$ & $2.21 \pm 0.12 * *$ \\
\hline
\end{tabular}

All values are presented as Mean $\_$SEM. ${ }^{* *} \mathrm{P}<0.001 ;{ }^{*} \mathrm{P}<0.01 ;{ }^{*} \mathrm{P}<0.05$ as compared to control

1. Steroid receptor expression
(A) Pituitary
(B) Hypothalamus
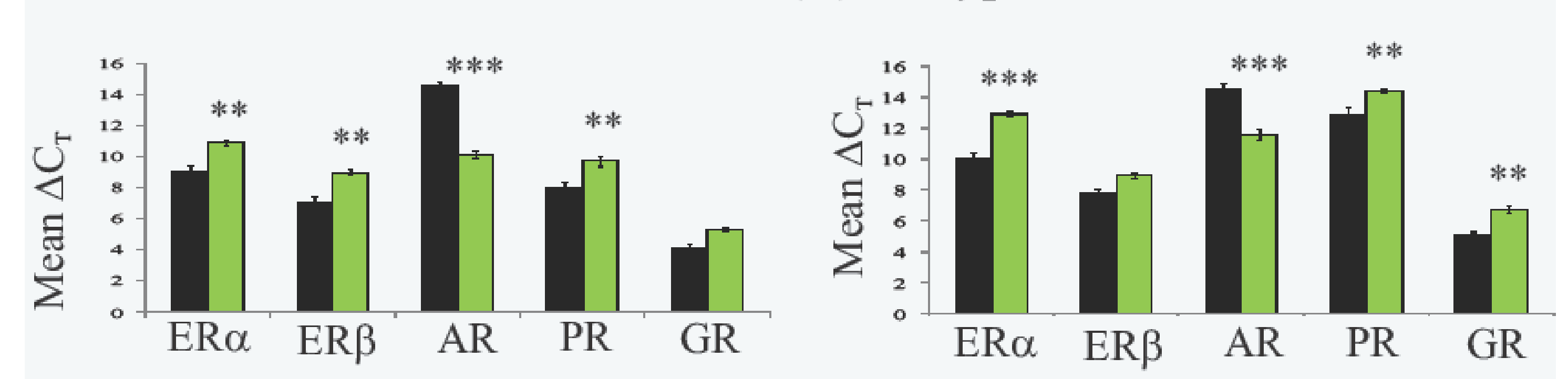

$\overparen{\mathrm{V}_{1}}$

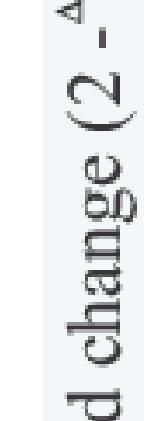

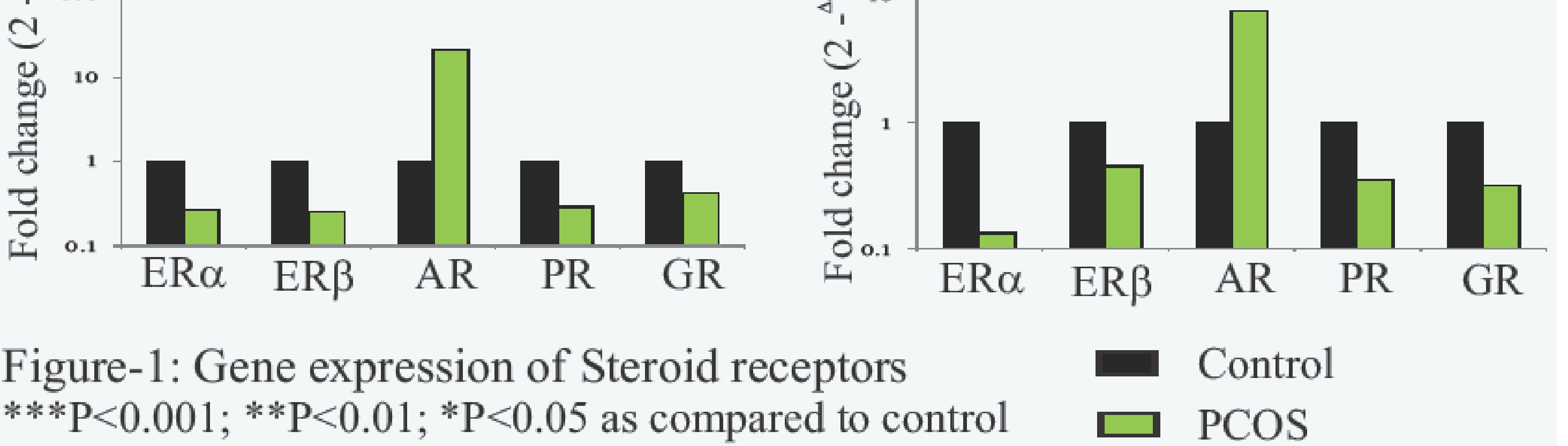

2. Status of Gonadotropins gene expression

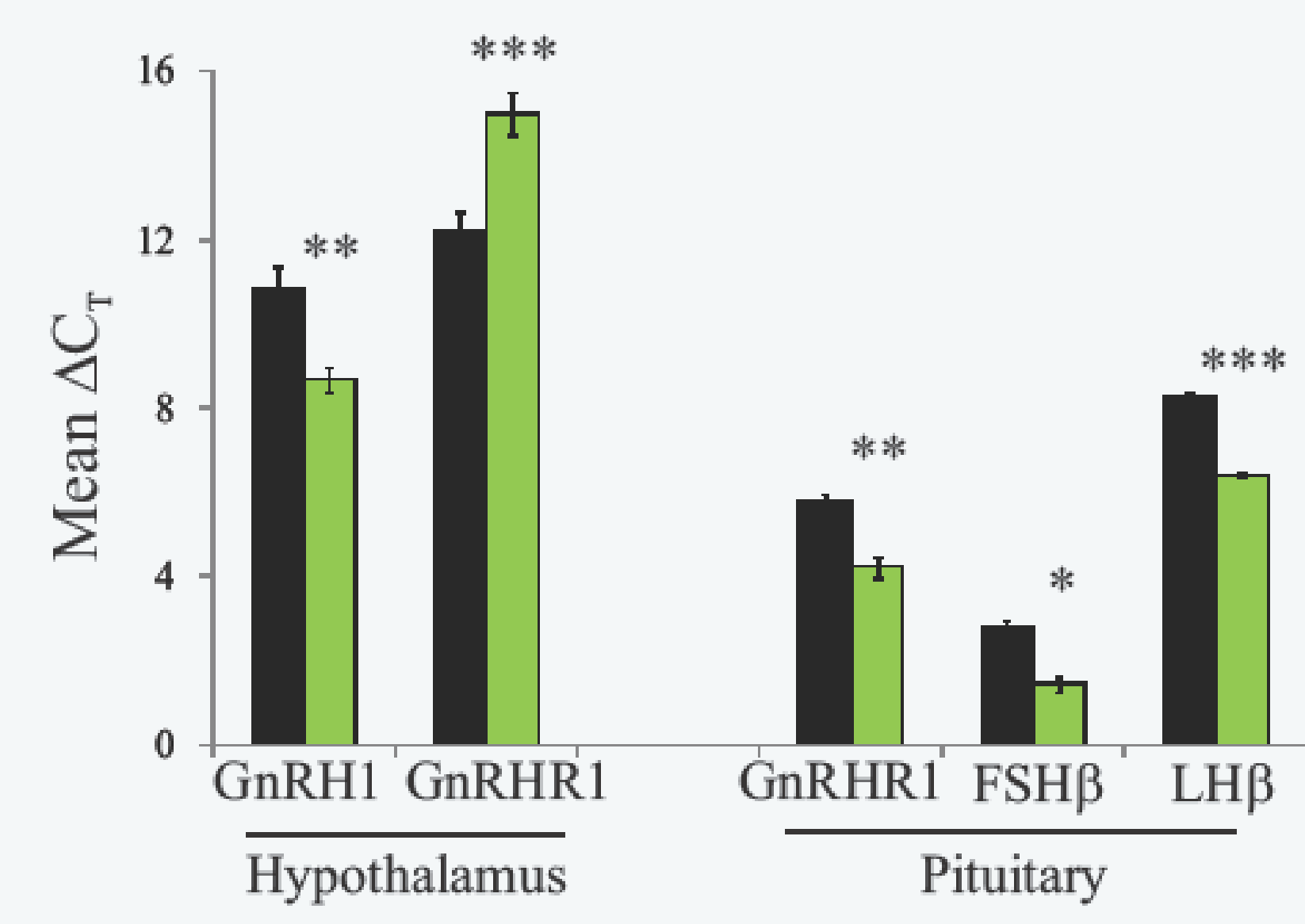

ש PContro

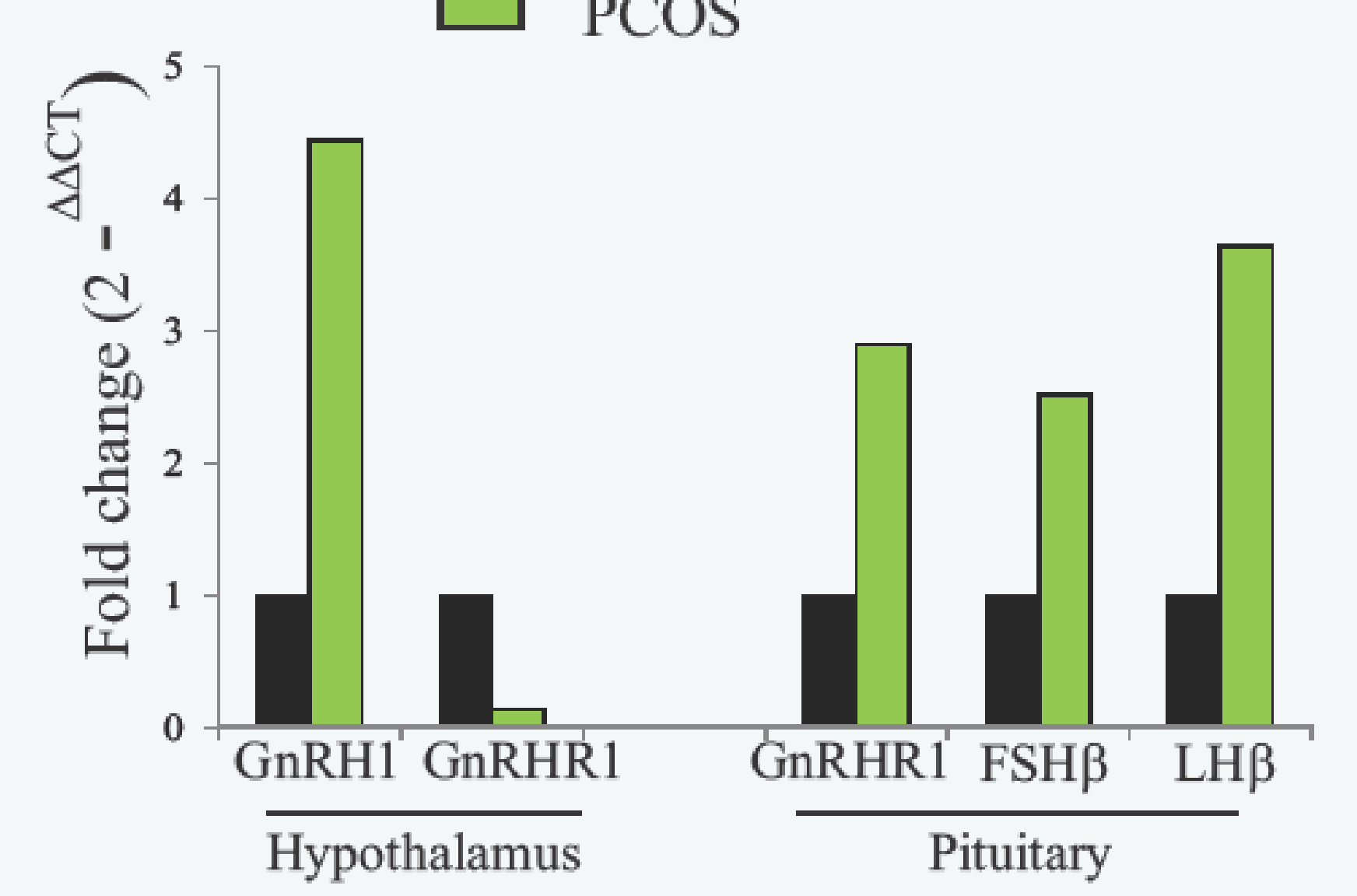

Figure-2. Gonadotropin gene expression $* * * \mathrm{P}<0.001 ; * * \mathrm{P}<0.01 ; * \mathrm{P}<0.05$ as compared to control
3. Gene expression of Stress regulators

(A) Pituitary

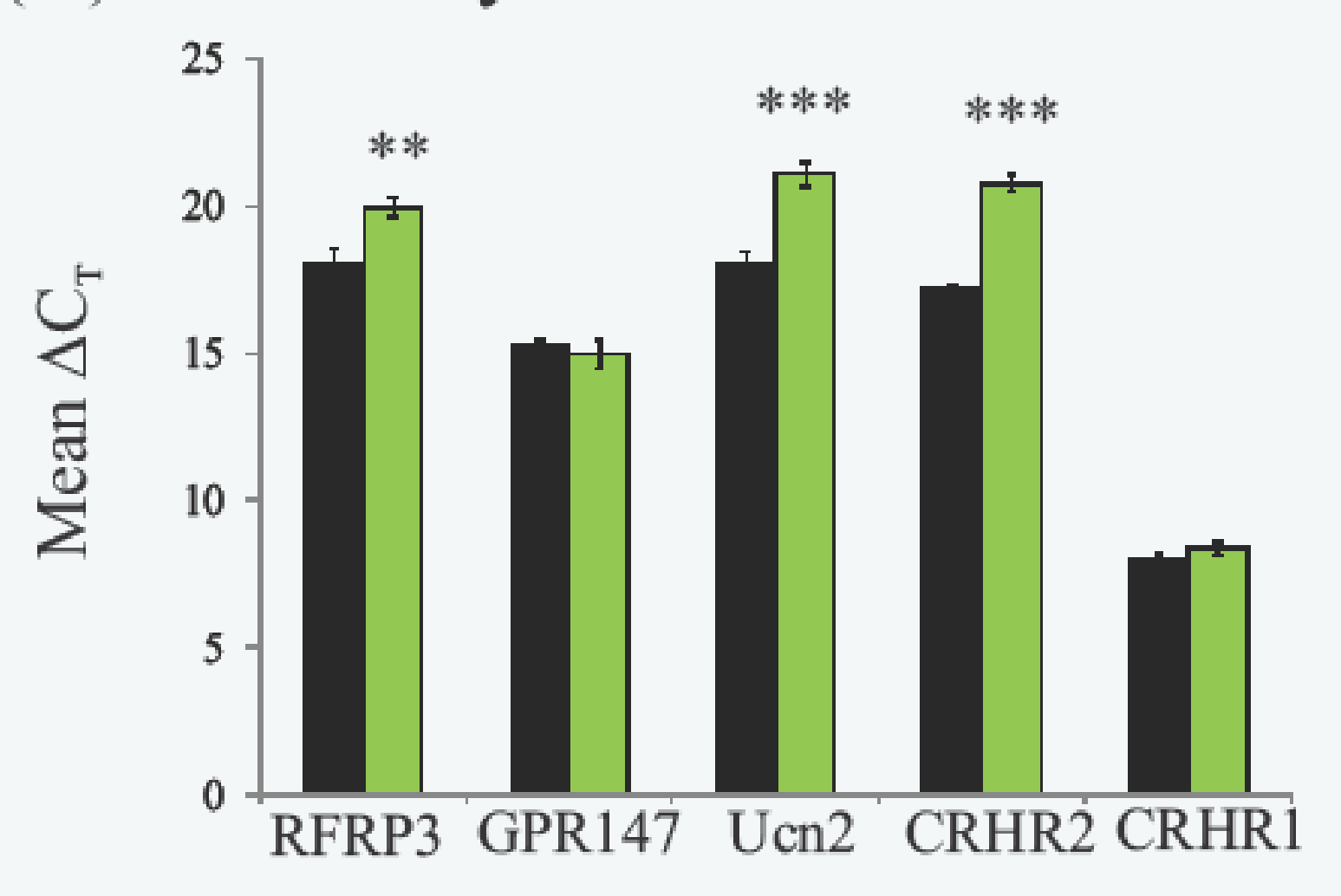

(B) Hypothalamus
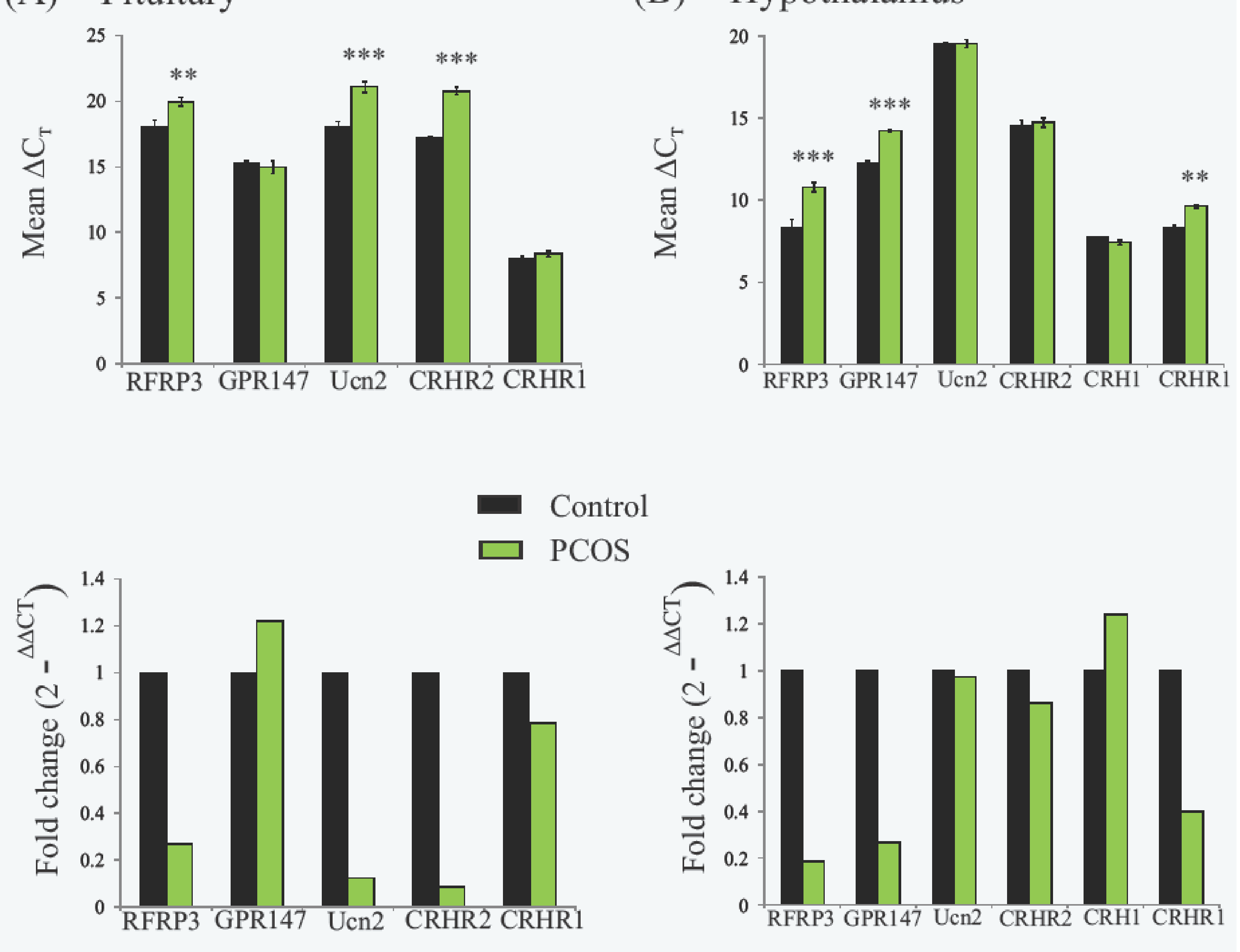

Figure-3. Real-Time PCR of important Stressors.

RFRP3: RF-amide related peptide 3

Ucn2 : Urocortin 2

$* * * \mathrm{P}<0.001 ; * * \mathrm{P}<0.01 ; * \mathrm{P}<0.05$ as compared to control

\section{Conclusion}

- Letrozole treated animals exhibited altered steroid hormone profile, disturbed estrus cyclicity and peripheral cysts in the ovary along with increased corticosterone levels, mimicking PCOS condition.

- In the study, increased brain glucocorticoid content with decreased expression of Glucocorticoid receptor indicates insensitivity of the feedback regulation of adrenal axis.

- Reduction in the transcripts of inhibitory neuropeptides -RFRP3 and Ucn2 along with their receptors was observed in pituitary resulting into higher gonadotropin content in PCOS.

\section{References:}

- Kafali H, Iriadam M, Ozardali I \& Demir N (2004) Archives of Medical Research 35,103-108.

- Ubuka T,Son YL,Tobari Y and Tsutsui K. (2012). Frontiers in Endocrinology, 3, 1-13

- Kageyama K. (2013)Frontiers in Endocrinology,4,1-12

- It is known that steroid receptors (ER, $\mathrm{PR}, \mathrm{AR}$ ) can modulate the above neuropeptides. Increased androgen receptor transcript along with decreased ovarian steroid receptor transcript could attribute to decreased feedback regulation of gonadal axis. Overall, the cumulative loss of inhibitory signals could be one of the reasons for increased GnRH release in PCOS.

- This is the first study wherein the cross-talk between adrenal and ovarian axis through neuropeptide has been elucidated. 